\section{HORNOS DE REDUCCIÓN DE COBRE Y BRONCE EN LA PRE Y PROTOHISTORIA DE LA PENÍNSULA IBÉRICA (1)}

\author{
COPPER AND BRONZE SMELTING \\ FURNACES IN THE PRE-AND \\ PROTOHISTORY OF THE IBERIAN \\ PENINSULA
}

PABLO GóMEZ RAMOS (*)

\section{RESUMEN}

En este trabajo se presentan las características principales de los hornos de reducción de minerales de cobre y estaño, cotejadas por vez primera con el estudio analítico de restos metalúrgicos hallados en la Península Ibérica desde el Calcolítico hasta la romanización. Tras la crítica bibliográfica y el análisis empírico llevados a cabo se establece como aportación que la vasija-horno fue el método más comúnmente empleado a lo largo de la Pre y Protohistoria peninsular tanto para la producción de cobre como de bronce.

\begin{abstract}
This work shows the main features of smelting furnaces for copper and tin ores, for the first time compared with the analytical study of metallurgical debris
\end{abstract}

$\left(^{*}\right)$ Becario del Programa Sectorial de Formación de Profesorado Universitario y Personal Investigador. Universidad Autónoma de Madrid. Facultad de Filosofía y Letras. Departamento de Prehistoria y Arqueología. Cantoblanco. 28049 Madrid.

El artículo fue remitido en su versión final el 21-XII-95.

(1) Este trabajo se enmarca dentro de la investigación llevada a cabo en el Proyecto PB92-0315: "Arqueometalurgia de la Península Ibérica: tecnología y cambio cultural durante la Edad del Bronce" dirigido por los profesores M. FernándezMiranda y G. Delibes, y es parte de la Tesis Doctoral del autor (Gómez Ramos, 1995). found in the Iberian Peninsula, dated from Chalcolithic up to Roman time. After the bibliographic criticism and the empirical analysis carried out, as a contribution it can be established that the crucible-furnace was the most common method used both for copper and bronze production, during Iberian Pre-and Protohistory.

Palabras clave: Análisis espectrográficos. Calcolítico. Edad del Bronce. Edad del Hierro. Hornos. Metalurgia. Península Ibérica. Vasijas-horno.

Key words: Spectrographic analysis. Chalcolithic. Bronze Age. Iron Age. Furnaces. Metallurgy. Iberian Peninsula. Crucible furnaces.

\section{INTRODUCCIÓN}

La metalurgia peninsular ha sido estudiada desde muchos puntos de vista, principalmente en lo que atañe a tipologías y composición de metales. Sin embargo, un tema en gran medida descuidado es el referido a los procesos tecnológicos de la producción de metal. Apenas existen estudios sobre elementos primarios tales como escorias, lingotes u hornos de fundición. La carencia explicativa en estos temas ha llevado a los 
arqueólogos, como práctica habitual, a reconstrucciones de hornos y procesos de fundición que, sin desmerecer los intentos, no siempre son acertados desde el punto de vista técnico y demuestran el desconocimiento teórico en este campo. A tenor de este panorama emprendimos una exhaustiva investigación sobre la tecnología metalúrgica basada en una revisión y crítica bibliográfica y apoyada en análisis de laboratorio (fluorescencia de rayos $\mathrm{X}$, microscopía óptica y electrónica y análisis ceramológicos) de materiales relacionados con la fundición primaria procedentes de más de 120 yacimientos de toda la Pre y Protohistoria de la Península Ibérica (Gómez Ramos, 1995). Aunque allí estudiamos también otras producciones como hierro y plata, en este artículo nos hemos centrado únicamente en el trabajo del cobre y del bronce.

En el tema de la fundición en hornos antiguos, los trabajos experimentales llevados a cabo en laboratorios o recreados en el terreno por avezados arqueometalúrgicos, en su mayoría extranjeros, así como la observación etnográfica han permitido que los procesos de fundición sean hoy día conocidos en detalle $\mathrm{y}$, con las precauciones necesarias, muchas de sus conclusiones extrapolables a la fundición prehistórica y antigua.

En toda esta problemática subyace sin duda la dificultad que implica reconocer e identificar arqueológicamente las estructuras de hornos, que han llegado a nuestros días casi siempre en condiciones precarias. No existen muchas veces indicios claros para asegurar si nos encontramos ante un horno y si lo es, cuál sería su finalidad. El problema se agudiza ante restos de suelos rubefactados de forma circular, pero sin evidencias metalúrgicas seguras. Tahonas, hornos de cocción cerámica, etc., dejan muchas veces áreas cenicientas o quemadas que pueden perfectamente confundirse e identificarse profanamente como estructuras metalúrgicas.

Pero si es complicado distinguir un horno metalúrgico de otro de finalidad indeterminada, igualmente difícil es, muchas veces, proceder a la diferenciación entre hornos de reducción de minerales y hornos de fundición de metales. Craddock (1989: 193, fig. 8.2) recoge una serie de factores a tener en cuenta en este sentido. Los hornos de reducción se caracterizan por tener un diámetro inferior a los $60 \mathrm{~cm}$., elementos refractarios empleados (revestimientos, toberas...) fuertemente vidriados y escoriados, una pobre conservación de las estructuras, proximidad a las fuentes de mineral y su asociación a grandes cantidades de escorias. Por el contrario, los hornos de fundición de metal tienen fuerte vidriosidad pero poca escoriación, suelen llevar asociados objetos utilizados en el trabajo del metal: crisoles, moldes, etc. y aparecen en áreas de talleres.

Destacamos estos aspectos porque la identificación y análisis de los hornos metalúrgicos se presenta como una labor complicada. Con el objetivo de paliar, en la medida de lo posible, esas carencias y evitar conjeturas imposibles desde el punto de vista práctico, damos a conocer lo más destacado y riguroso que se ha escrito sobre este tema, que servirá de punto de arranque con cuyos datos cotejar los hallazgos arqueológicos y los restos estudiados analíticamente dentro de nuestra investigación.

\section{CARACTERÍSTICAS TÉCNICAS Y TIPOLOGÍA DE LOS HORNOS DE REDUCCIÓN Y FUNDICIÓN}

Sucintamente puede decirse que un horno es una cámara donde se producen las transformaciones químicas que convertirán un mineral metalífero en metal. La propia dinámica de la fundición y los requisitos para llevarla a cabo hacen que todos los hornos, independientemente de los minerales que en él se procesen y del metal que de él se obtenga, compartan una serie de características técnicas comunes entre las que cabe señalar: el rendimento térmico del horno, el empleo de minerales y fundentes, y el procedimiento seguido para llevar a cabo la fundición.

En el rendimiento térmico influyen el combustible, la capacidad aislante de la estructura, el volumen del horno y una aireación adecuada. En la Pre y Protohistoria de Europa Occidental el combustible empleado es el carbón vegetal con el que se consigue la temperatura adecuada y un ambiente reductor (monóxido de carbono). Las pérdidas de calor se producen por conducción y convección, por lo que era normal que muchos hornos se enterraran en el suelo y que se construyeran con material re-

T. P., 53, n. ${ }^{\circ} 1,1996$ 
fractario (revestimientos arcillosos). En cuanto al volumen, los datos recogidos de la bibliografía especializada indican que se trataba siempre de estructuras de pequeña capacidad (en torno a unos $50 \mathrm{~cm}$. de diámetro) ya que con los sistemas de aireación utilizados y con el empleo de carbón vegetal, no se podían alcanzar ni mantener las temperaturas si los hornos fueran de mayor envergadura. La aireación se conseguía, bien mediante tiro natural, es decir, una corriente conseguida por la circulación de aire a través de orificios abiertos en determinados puntos de las paredes del horno, o tiro inducido o forzado artificialmente con tubos de soplado o fuelles, empleando toberas.

La riqueza del mineral así como la naturaleza y concentración de otros elementos asociados que forman la ganga inciden en el rendimiento, tiempo de fundición, temperatura necesaria y procedimientos para transformar el mineral en metal. Para ello son precisos tratamientos preliminares del mineral, que pueden ser físicos, como la trituración, enriquecimiento, etc., o químicos, previos a su conversión en metal (oxidación/tostación de los sulfuros, calcinación de los carbonatos) y/o durante su transformación en el horno (reducción de óxidos). En la fundición de minerales era práctica común el empleo de fundentes con el objetivo de obtener un silicato (escoria) de bajo punto de fusión. Suelen ser silicatados o ferruginosos, dependiendo de la naturaleza de la ganga, con contenidos de As, $\mathrm{Pb}, \mathrm{Co}$, etc. que pueden pasar al metal como elementos minoritarios y trazas.

Por lo que respecta al proceso de fundición, una vez construido y seco el horno, se procedía al caldeo, comprobándose así sus posibilidades y a continuación se cargaba de mineral y combustible en las proporciones adecuadas. El mineral se solía machacar para aumentar las superficies de contacto y con ello favorecer las reacciones de reducción. El tiempo de operación estaba en función de la capacidad del horno y se estima que duraba varias horas.

Las estructuras u hornos de reducción antiguos pudieron y debieron ser diversos. Sin embargo, aunque una primera sistematización parte de los propios minerales procesados, la variedad y el estado fragmentario de los restos arqueológicos dificulta en gran medida cual- quier intento de tipificación, se ve facilitado, no obstante, por los trabajos experimentales que a lo largo de muchos años se han venido realizando, recogidos concisamente por Tylecote y Merkel (1985) y por las evidencias etnográficas.

Una de las primeras divisiones generales fue realizada por Forbes en 1964 (1971: 122-132) que según el tamaño de las estructuras individualizó los hornos antiguos en los que estaba en contacto el mineral y el combustible en dos tipos básicos: hornos de hogar, cuando la altura es igual o menor que el diámetro, y hornos con chimenea cuando la altura es considerablemente mayor que el diámetro.

Sin embargo, como ha señalado Craddock (1989: 203), la diferenciación es más aparente que real ya que en ningún caso se ha preservado la construcción exterior. A problemas inherentes de degradación se une el desmantelamiento voluntario que sufría la mayoría de las estructuras, en orden a extraer el metal que quedaba depositado en el fondo. Si bien las complicaciones formales existen en cualquier división, podemos simplificar la tipología de los hornos de producción cobre/bronce destacando como tipos básicos y principales:

\subsection{Vasijas-horno}

Aunque en nuestro país ha sido un "descubrimiento" relativamente reciente desde la primera notificación dada por S. Rovira en 1987 (1989), trabajos experimentales, a partir de la lectura de los restos arqueológicos, estaban confirmando desde hacía tiempo que el tipo de horno más sencillo utilizado para reducir minerales con efectividad era una simple vasija o recipiente de barro, denominado en la bibliografía anglosajona con el término un tanto equívoco de "crucible furnace". Se trata de vasijas de pastas groseras, sin una preparación o tratamiento especial destinadas a la metalización de minerales de cobre. Morfológicamente son piezas cerámicas de mayor tamaño que el habitual de un crisol y por lo general suelen tener formas muy abiertas. La producción obtenida en estas vasijas-horno suele ser nódulos o goterones de metal embebidos en una masa compuesta por "escoria", minerales de cobre 
parcialmente reducidos y restos de combustible a medio quemar formando los denominados conglomerados de horno (Bachmann, 1980). Para extraer el material del horno era necesario romper la cerámica, de ahí que sólo encontremos en el registro arqueológico los fragmentos. Mediante el machacamiento de esta masa se lograba desgajar del compuesto escoriáceo, los nódulos de metal que se fundían posteriormente en crisoles.

Tylecote (1974: 54) demostró que la reducción de minerales de cobre (óxidos y carbonatos) no implicaba dificultades siempre que no se tratara de sulfuros de cobre. Otros investigadores continuaron en la misma línea confirmando estos resultados. Así, por ejemplo, a principios de los años 80 Khalil y Bachmann (1981), tras el hallazgo de minerales parcialmente reducidos y goterones de metal en el yacimiento palestino de Jericó llevaron a cabo un experimento similar.

Aspectos puntuales de la fundición en estos vasos han sido señalados por otros autores. Así el estudio de recipientes similares hallados en el poblado de Los Millares demuestra que la fuente de calor era interna, con el objetivo beneficioso de que al mantener la superficie exterior fría se produzca la rigidez y tensión suficientes que eviten la rotura del recipiente cuando éste se somete a temperaturas altas (Hook et alii, 1991: 68).

También dentro de los trabajos experimentales cabe destacar el llevado a cabo por Zwicker et alii (1985), por su doble interés: por un lado, el haber demostrado la posibilidad de la tostación y reducción de sulfuros de cobre en vasijas, y por otro, el haber recogido pruebas arqueológicas que atestiguan la pervivencia de este tipo de horno hasta momentos muy avanzados. En efecto, hallazgos de vasijas en contextos del Bronce Antiguo en Norsun Tepe (Anatolia) o del Bronce Final en Enkomi y Kition (Chipre), algunas estas últimas con un agujero para la introducción de la tobera, reflejan una continuidad en su utilización como hornos de reducción en distintas zonas para la obtención de cobre, bronce e incluso latón en época romana.

Con el refrendo de estos trabajos se han podido identificar numerosos hallazgos de fragmentos de vasijas groseras con adherencias es- coriaceas y huellas térmicas, procedentes de las excavaciones arqueológicas y descritos en la bibliografía durante mucho tiempo como crisoles de fundición.

Si bien la duración del tratamiento, los minerales empleados, la destreza del fundidor, etc. determinarán la mayor o menor eficacia del proceso, los experimentos han demostrado, y la arqueología lo ha corroborado, que la reducción de minerales de cobre a metal es factible con el empleo de una sencilla vasija de cerámica, minerales ricos en metal y una tobera dirigida hacia la carga. La facilidad y rapidez en su elaboración y un trabajo de mantenimiento prácticamente nulo determinaron, posiblemente, que fuera un método utilizado durante mucho tiempo para la obtención del metal en zonas retardatarias desde el punto de vista metalúrgico.

\subsection{Hornos en hoyo excavado u hornos-cuenco}

Otro tipo de horno sencillo, no necesariamente posterior en el tiempo, consistió en la excavación de un hoyo en el suelo. Son los primitivos "hole in the ground" o también "open fire" (Forbes, 1971: 126) que perdurarán hasta época romana conviviendo con tipos más sofisticados. En este caso hoyos abiertos de forma circular y fondo cóncavo ("bowl furnace") con un diámetro entre 20 y $50 \mathrm{~cm}$. eran excavados en la tierra, a veces, revestidos de arcilla, para realizar la función de cámara de reducción. Para desalojar la escoria y lograr sacar el metal depositado en el fondo por ser de mayor densidad, era necesario romper la estructura, por lo que la operación de recubrimiento del hoyo e incluso su excavación debía volver hacerse, sirviendo por tanto, al igual que en el caso de las vasijas-horno para una sóla operación.

Los hornos calcolíticos del sitio 39 de Timna (Sinaí), a base de hoyos de $45 \mathrm{~cm}$. de diámetro por $45 \mathrm{~cm}$. de profundidad cavados en el suelo y con goterones de metal embebidos en escorias no sangradas (Rothenberg, 1985 y 1990) datados en el IV milenio a.C.; los vestigios de fundición del III milenio a.C. en Tawi Aarja, Omán (Weisgerber, 1978) y los hornos hallados en distintas zonas mauritanas también de la Edad del Cobre (Lambert, 1983: 67) son distin-

T. P., 53, n. ${ }^{\circ} 1,1996$ 
tos ejemplos de hornos-hoyo con fondos de arcilla excavados a ras del suelo y por lo general con toberas asociadas.

Aunque en el caso de Tawi Aarja se han relacionado estos hornos con el hallazgo de lingotes-torta de peso entre 1,5 y $3 \mathrm{~kg}$. lo cierto es que los restos de metal conservados en el interior de los hornos y los trabajos experimentales demuestran que la producción en estos sencillos hornos debía ser mucho menor (goterones o nódulos de cobre embebidos en una escoria pastosa sin sangrar). En la misma idea inciden otros experimentos infructuosos y que han señalado también la importancia del ambiente reductor creado por una cámara envolvente excavada o no y la necesidad de un tiro artificial aportado al menos por una tobera (Coghlan, 1975: 28-29).

\subsection{Hornos con cámara exterior}

Progresivamente los hornos fueron mejorando sus capacidades técnicas mediante la construcción de un cuerpo superior de altura y forma variable (troncocónica, abovedada, circular formando una chimenea, etc.). Aunque fueron siempre hornos de pequeño diámetro y de fondo excavado en el suelo se trata ya de hornos de mayor volumen que presentan como características principales el tiro forzado por una o más toberas así como canales y pozos para el sangrado de las escorias, aunque esta última característica no es imprescindible. Su interpretación se basa no tanto en los vestigios arquitectónicos recobrados como en la producción rescatada: lingotes-torta y escorias de sangrado. Ambos productos requieren temperaturas elevadas y acreditan una producción mayor y mejorada que la obtenida en hornos más simples.

El principio de obtención del metal sigue siendo muy sencillo. Así, debido a que el cobre tiene mayor densidad (su peso específico es 8,89 ) se depositaba en el fondo mientras que la escoria, más ligera, de peso específico en torno a 4, sobrenadaba encima del lingote. Las temperaturas para la licuación del cobre es de $1.084^{\circ} \mathrm{C}$ y la de la escoria de unos $1.150^{\circ} \mathrm{C}$, por lo que la escoria fundida indica hornos donde la temperatura debió ser superior a esa cifra.
Hacia el final de la operación la escoria es extraída abriendo un camino hacia afuera a través de un agujero o piquera de sangrado. Una vez que se ha enfriado el horno se extrae la torta del fondo para lo cual es necesario muchas veces desmantelar la superestructura.

Si bien depende del grado de desarrollo tecnológico alcanzado, los hornos con chimenea parecen tener su punto de arranque en el Bronce Final ya que hornos de este tipo se localizan en el siglo XII a.C. en Timna (Tylecote, 1980: 190-191) y los hornos de reducción de minerales de cobre hallados en Nigeria se fechan a partir del 800 a.C. (Grébénart, 1983: 112; 1988: 121-123).

Para finalizar este apartado hemos de referirnos, aunque sea brevemente, a los hornos de fundición de metal. Una vez conseguida la reducción, el licuado o fusión del cobre $\left(1.083^{\circ} \mathrm{C}\right)$ o del bronce $\left(950^{\circ} \mathrm{C}\right)$ es una labor mucho más rápida y sencilla. Los hornos utilizados para la fundición en crisoles no eran excesivamente complejos ya que sólo se requiere un fuego vivo en el que calentarlos (Bernus, 1983: 165-166; Sarabia, 1992: 18).

La simplicidad lleva a que el registro arqueológico sea por lo tanto parco en hallazgos. Empero, Tylecote (1976: 17) recoge como uno de los hornos de fundición más antiguos el hallado en el sitio calcolítico de Abu Matar, Israel entre el 3300-3000 a.C. Se trata de pequeños hornos circulares de $30-40 \mathrm{~cm}$. de diámetro con paredes de unos $12-15 \mathrm{~cm}$. de altura y $3 \mathrm{~cm}$. de espesor en cuyo interior se calentaría el crisol en una estructura sencilla a modo de brasero. Otro ejemplo de horno de fundición de metal lo proporciona los hornos del Bronce FinalHierro Antiguo hallados en Timna, consistentes en una especie de cistas formadas por 4 piedras cuyo interior apareció relleno de cenizas (Tylecote, 1980: 198).

\section{HALLAZGOS DE HORNOS DE REDUCCIÓN EN LA PENÍNSULA IBÉRICA}

\subsection{Calcolítico y Bronce Antiguo}

El número de referencias sobre hornos de reducción en la Península Ibérica recabado de 
la bibliografía es relativamente abundante. Para los períodos más antiguos, Calcolítico y Bronce Antiguo se ha señalado numerosos hallazgos, si bien un análisis crítico y atento evidencia identificaciones que en la mayor parte de los casos han de ser desestimadas, bien por falta de pruebas, bien porque las que hay no son concluyentes en modo alguno.

Los hallazgos más antiguos cuentan en efecto, con reconstrucciones imposibles que deben contextualizarse en la época en que se hicieron, donde apenas había estudios dedicados a hornos metalúrgicos. En concreto, nos referimos a los hornos del Cerro de las Canteras, Almizaraque y Mas de Menente. En el primero de los casos Motos (1918: 57-60) apunta una construcción abovedada construida con arcos y tortas de arcilla agujereadas. Ponsell (1926: 8) y Luis Siret (1948: 119) presentan reconstrucciones similares para los yacimientos de Mas de Menente (Alicante) y Almizaraque (Almería) respectivamente. El horno de Mas de Menente, adscrito al Bronce Medio-Pleno, trata de un ejemplo muy similar a la reconstrucción otorgada por Siret para hornos de fundición de plata en Almizaraque donde intervenían también bóvedas de arcos yuxtapuestos y tubos de barro a modo de chimeneas.

A estos hallazgos hay que unir otras identificaciones basadas en restos cuando menos escasos. Así se cita un posible horno para fundir cobre en el horizonte campaniforme del Cerrillo de Ciavieja, basado únicamente en el hallazgo de unos trozos de piedra y adobes endurecidos próximos a escorias de cobre (Carrilero y Suárez, 1989-90: 125). En el caso de Chinflón un trozo de piedra con escoria adherida fue interpretada como vestigio de un horno de fundición (Rothenberg y Blanco, 1980: 52; Blanco y Rothenberg, 1981: 35-41), pero imposible de determinar formal e incluso cronológicamente por la mezcla y procedencia heterogénea de materiales hallados en el yacimiento. Los restos de hornos en Los Millares son también exiguos ya que se basan únicamente en el hallazgo de elementos de combustión en uno de los casos y en el otro en la proximidad de fragmentos de crisoles y de gotas de metal a una estructura circular (Arribas et alii, 1987: 253-254; Molina et alii, 1986: 189-191).
Las referencias de los hornos del Calcolítico final del Amarguillo II son también ambigüas. El descubrimiento de supuestas escorias y minerales de cobre en las proximidades de unas estructuras de barro de tendencia circular, una de grandes dimensiones y rellena de cal $(\mathrm{Ca}-$ brero, 1987: 181-182, 184 y 1990: 276) no son indicios suficientes para considerarlas directamente como hornos de fundición.

Otras menciones son, por el contrario, demasiado imprecisas. En el Castelo de Santa Justa se alude al hallazgo de restos de revestimiento y de fundición en una estructura cerámica mal definida (Gonçalves, 1989: 278-283, 481). En el caso de los hornos de Zambujal la identificación se basa en indicios escasos tales como la aparición de gotas de cobre y piezas de metal en manchas oscuras dentro de varias construcciones circulares (Sangmeister y Schubart, 1981: 62). Más aún, cerca de las mismas se localizaron restos alimenticios que podrían probar también la posible utilización de estos hogares en tareas de cocina (Schubart y Sangmeister, 1984: 31). En Cabeço da Erra el único descubrimiento de una mancha particularmente oscura sirvió para pensar en indicios de un posible horno (Gonçalves, 1983-1984: 71, 73 y 75).

Se ha apuntado igualmente dos supuestos hornos de fundición en los niveles campaniformes de El Ventorro. En concreto, en la cabaña 21 apareció un hogar con huellas de combustión formado por piedras que trazan un media circunferencia mientras que en la cabaña 13 apareció un conjunto circular de cerámica, piedras y bloques de barro de unos $60 \mathrm{~cm}$. de diámetro cerca del cual se recogieron fragmentos de crisoles y gotas de cobre (Priego y Quero, 1992: 300), y que en un principio, se consideraron como estructuras residuales donde se llevaba a cabo el calentamiento de las vasijas y crisoles. Sin embargo, no hay que olvidar que estos recipientes no muestran señales de fuego en su cara externa, por lo que la carga del combustible y su calentamiento se realizó únicamente desde el interior, lo que podría indicar que muchos de los crisoles señalados son realmente recipientes de reducción.

La analítica espectográfica y microscópica del Proyecto de Arqueometalurgia ha demostrado que el horno más empleado en estos mo- 


\begin{tabular}{|c|c|c|c|c|c|c|c|c|c|c|}
\hline Análisis & Yacimiento & $\mathrm{Cu}$ & $\mathrm{Fe}$ & As & $\mathrm{Sb}$ & Sn & $\mathrm{Pb}$ & $\mathrm{Ag}$ & $\mathrm{Ni}$ & $\mathrm{Zn}$ \\
\hline AA1080A & Almizaraque, Cuevas del A. (Almería) & $69 ’ 84$ & $5 ’ 63$ & $18^{\prime} 91$ & $1 ’ 25$ & $0 ’ 05$ & nd & nd & $0 ’ 62$ & $0 ’ 56$ \\
\hline AA1081 & Almizaraque, Cuevas del A. (Almería) & $68 ’ 51$ & 3’64 & $22 ’ 75$ & $1 ' 85$ & nd & nd & 0’018 & $0 ’ 45$ & $0{ }^{\prime} 55$ \\
\hline AA1082 & Almizaraque, Cuevas del A. (Almería) & 93’03 & $1 ' 52$ & 3’05 & $0 ’ 04$ & $0 ’ 04$ & $0 ’ 33$ & 0’007 & $0 ’ 39$ & nd \\
\hline AA1085B & Almizaraque, Cuevas del A. (Almería) & $75^{\prime} 11$ & $3 ’ 93$ & $16{ }^{\prime} 87$ & $0 ’ 92$ & $0 ’ 03$ & $0 ’ 15$ & nd & $0 ’ 50$ & $1 ’ 00$ \\
\hline AA1090 & Almizaraque, Cuevas del A. (Almería) & $51 ’ 16$ & 9'41 & $33 ’ 58$ & $2 \nmid 45$ & nd & nd & 0’021 & $0 ’ 42$ & 0 '47 \\
\hline AA1094 & Almizaraque, Cuevas del A. (Almería) & 63'84 & $8 ’ 22$ & $19^{\prime} 84$ & $1 ’ 21$ & $0 ’ 04$ & $4 ’ 35$ & nd & $0 ’ 26$ & 0’11 \\
\hline AA1097 & Almizaraque, Cuevas del A. (Almería) & $61 ' 69$ & $3 ’ 28$ & $15^{\prime} 91$ & 0’80 & $0 ’ 04$ & $14^{\prime} 95$ & 0’006 & $0 ’ 33$ & nd \\
\hline AA1104B & Almizaraque, Cuevas del A. (Almería) & $91 ’ 41$ & 2’11 & 3'80 & 0,56 & 0’01 & $0 ’ 22$ & 0’004 & $0 ’ 36$ & $0 ’ 09$ \\
\hline PA2237 & Almizaraque, Cuevas del A. (Almería) & $67 ’ 88$ & $6 ’ 30$ & $21 ’ 7$ & $1 ’ 02$ & nd & $0 ’ 28$ & 0’008 & $0 ’ 41$ & 1774 \\
\hline PA2238 & Almizaraque, Cuevas del A. (Almería) & $52 ’ 10$ & 9'34 & 34 '8 & 1 '99 & nd & nd & $0 ’ 043$ & $1 ’ 11$ & $0{ }^{\prime} 41$ \\
\hline PA3773 & Almizaraque, Cuevas del A. (Almería) & $65 ’ 70$ & $7>75$ & $23 ’ 61$ & $1 ’ 00$ & nd & nd & 0’070 & $1 ’ 20$ & $0{ }^{\prime} 60$ \\
\hline PA6246A & Almizaraque, Cuevas del A. (Almería) & $52{ }^{\prime} 49$ & 14 '86 & $21 ' 54$ & 2’14 & nd & $8 ’ 91$ & nd & nd & nd \\
\hline PA5035 & Cerro del Prado, Sierra de Baza & $19 ’ 4$ & $80 ’ 3$ & $\operatorname{tr}$ & 0’025 & nd & nd & nd & nd & nd \\
\hline PA6270 & Cerro Virtud, Cuevas del A. (Almería) & $42 ’ 04$ & $11 ’ 29$ & $16 ’ 10$ & $1 ’ 71$ & nd & $28 ’ 46$ & 0’071 & nd & $0{ }^{\prime} 32$ \\
\hline PA6272 & Cerro Virtud, Cuevas del A. (Almería) & det & det & nd & det & nd & det & nd & - & nd \\
\hline PA4787 & Los Cortijillos, Sierra de Baza & $46{ }^{\prime} 58$ & 49’81 & 3'52 & 0’035 & nd & nd & nd & nd & nd \\
\hline PA4965 & Los Cortijillos, Sierra de Baza & $74^{\prime} 81$ & $11 ’ 10$ & $14^{\prime} 04$ & 0’039 & nd & nd & 0’016 & nd & nd \\
\hline PA4966 & Los Cortijillos, Sierra de Baza & $88 ' 59$ & 9’41 & $1 ’ 94$ & 0’050 & nd & nd & 0’003 & nd & nd \\
\hline PA4988 & Los Cortijillos, Sierra de Baza & $58 ’ 66$ & $39 ’ 46$ & 178 & 0’032 & nd & nd & nd & nd & nd \\
\hline PA4989 & Los Cortijillos, Sierra de Baza & $19 ’ 59$ & $80 ’ 42$ & nd & nd & nd & nd & nd & nd & nd \\
\hline PA4990 & Los Cortijillos, Sierra de Baza & $88 ’ 41$ & - & $11 ’ 36$ & $0 ’ 230$ & nd & nd & nd & - & nd \\
\hline PA5313 & Llanete de los Moros, Montoro (Córdoba) & $79 ’ 75$ & $14 ’ 39$ & nd & 0’041 & 5795 & nd & nd & nd & nd \\
\hline PA1080 & La Alameda, Peleagonzalo (Zamora) & 99'88 & - & $\operatorname{tr}$ & $\operatorname{tr}$ & nd & nd & nd & - & nd \\
\hline PA1083A & La Alameda, Peleagonzalo (Zamora) & $98 ’ 86$ & - & nd & $0 ’ 553$ & nd & nd & $0 ’ 024$ & - & 0'16 \\
\hline PA1083B & La Alameda, Peleagonzalo (Zamora) & $99 ’ 14$ & - & nd & $0 ’ 252$ & nd & nd & nd & - & nd \\
\hline PA4054 & Cueva de la Vaquera, Torreiglesias (Segovia) & det & det & & det & det & & det & & det \\
\hline PA0670A & Arenero de Soto, Getafe (Madrid) & $27 ' 58$ & $25{ }^{\prime} 97$ & $11 ’ 42$ & 0’390 & nd & $33 ’ 23$ & 0’087 & nd & nd \\
\hline PA0670B & Arenero de Soto, Getafe (Madrid) & $44^{\prime} 25$ & 2’75 & $24 ’ 84$ & 0’280 & nd & $25^{\prime} 44$ & 0’070 & nd & nd \\
\hline PA0670D & Arenero de Soto, Getafe (Madrid) & $800^{\prime} 50$ & $3 ’ 24$ & 3’97 & $0 ’ 370$ & nd & 8770 & 0’195 & $0 ’ 51$ & nd \\
\hline PA0670E & Arenero de Soto, Getafe (Madrid) & $80 ’ 98$ & $1 ' 40$ & $4 ’ 39$ & $0 ’ 560$ & nd & $8 ’ 27$ & $0 ’ 250$ & nd & nd \\
\hline AA1246A & El Ventorro, Getafe (Madrid) & $92 ’ 06$ & 2’93 & $4 ’ 25$ & 0’027 & 0’193 & $0 ’ 28$ & 0’012 & $0 ’ 35$ & nd \\
\hline PA3047 & Yacimiento $\mathrm{n}^{\circ} 4$, Villaviciosa de O. (Madrid) & 6526 & $17 ’ 84$ & $11 ' 89$ & nd & $5 ’ 07$ & nd & nd & nd & nd \\
\hline PA3048 & Yacimiento $\mathrm{n}^{\circ} 4$, Villaviciosa de O. (Madrid) & $24 ' 37$ & $49 ’ 57$ & $22 ’ 56$ & 0’066 & $0 ’ 364$ & $2 ’ 50$ & 0’107 & nd & nd \\
\hline PA4783 & Yacimiento 35/40, Carabaña (Madrid) & $85^{\prime} 88$ & $13 ’ 10$ & nd & 0’006 & 1’01 & nd & nd & - & nd \\
\hline PA6324 & Bauma del Serrat, Tortellá (Gerona) & $91 ’ 70$ & nd & $0{ }^{\prime} 746$ & 6’890 & 0’606 & nd & 0’059 & nd & nd \\
\hline PA6325 & Bauma del Serrat, Tortellá (Gerona) & $99^{\prime} 72$ & nd & nd & $0 ’ 212$ & nd & nd & 0’062 & nd & nd \\
\hline PA6328 & Bauma del Serrat, Tortellá (Gerona) & det & & & det & & & & & \\
\hline
\end{tabular}

Tabla 1. Análisis elemental de adherencias en vasijas-hornos del Calcolítico y Bronce Antiguo, despreciando la ganga (\% en

mentos es la vasija-horno, no habiéndose recogido hasta la fecha restos de revestimientos que pudieran indicar la utilización de hornos de otro tipo. Los análisis cuantitativos figuran en la tabla 1. Éstos y los de las siguientes tablas han sido realizados por la técnica espectrométrica de fluorescencia de rayos $\mathrm{X}$ (energía dispersiva), directamente sobre la superficie escorificada, en el I.C.R.B.C. (Madrid). No se ha podido determinar el contenido de silicio y otros elementos ligeros, componentes importantes de la escoria. Los resultados, ajustados para sumar
100 , no son representativos de la escoria como tal, sino de una "aleación teórica", y pueden usarse con fines comparativos con análisis de minerales y metales efectuados por el mismo método. La cronología concreta de los materiales, fruto en su mayor parte de excavaciones, viene determinada por la información facilitada por los excavadores al solicitar los análisis, la mayoría de los cuales son inéditos.

En todos los casos se trata de vasijas similares a las de uso doméstico que presentan adherencias escoriáceas por su cara interna y de ta- 


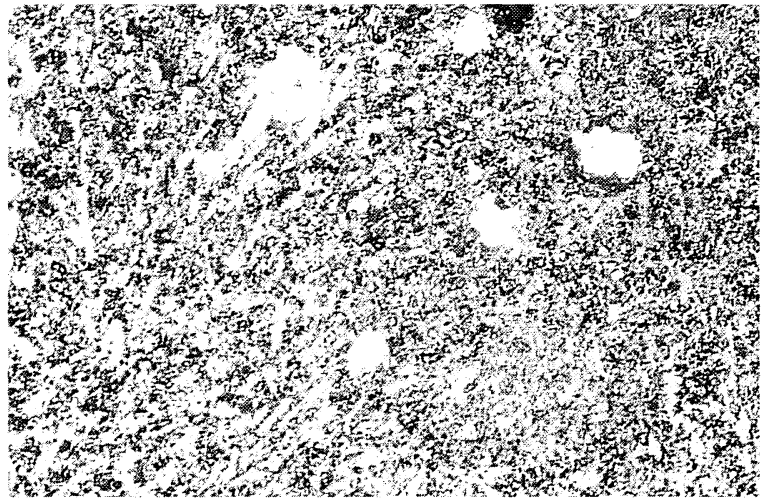

Lám. I. Microfotografía de la sección de la vasija-horno PA3047 del Yacimiento $n^{\circ} 4$ de Villaviciosa de Odón. Inclusiones de cobre (color blanco) en una matriz silícica donde se observan formaciones aciculares de fayalita y nodulillos blanquecinos de wustita y magnetita. 100x.

maño superior al de los crisoles. Por los análisis se observa el procesamiento reductor de minerales oxídicos de cobre con contenidos variables en hierro, plomo y arsénico dependiendo del polimetalismo de los minerales de partida. En el caso del hierro, es normal una pérdida acusada en el paso del mineral al metal, eliminado a través de la escoria. El ambiente excesivamente oxidante de estos hornos motivaba la formación de estructuras ferromagnéticas, corroboradas por la presencia de wustita y magnetita en goterones de metal bruto que junto con estructuras fayalíticas indican temperaturas del orden de $1100^{\circ} \mathrm{C}$ (Lám. I). Otro metal atrapado en la escoria es el plomo aunque gran parte se pierde en los humos en forma de óxido gaseoso. También el arsénico queda como elemento remanente en las adherencias cerámicas, bien a través de la formación de speiss, bien porque los óxidos volátiles han impregnado el material poroso de la escoria y de la pasta cerámica. Existen también varios ejemplos, como una vasija del Llanete de los Moros y otra del Yacimiento $n^{\circ} 4$ de Villaviciosa de Odón, donde se observa la utilización de minerales con estaño pero que debido a que las condiciones del horno no eran las adecuadas no se aleó de forma natural con el cobre, perdiéndose en su mayoría en la formación de la escoria.
Del estudio espectográfico y sobre todo, microscópico de estas vasijas y de los minerales y productos de fundición obtenidos en ellas se deduce que los minerales de cobre eran desmenuzados para aumentar la superficie de contacto con el agente reductor (carbón y monóxido de carbono) y se avivaba el hogar con la ayuda de tubos de soplado o fuelles. De este modo se conseguían temperaturas entre $1.100^{\circ}$ y $1.200^{\circ}$ $\mathrm{C}$, suficientes para fundir, como hemos observado repetidamente, los minerales - aunque éstos se reducen a temperaturas inferiores-y escoriar la poca ganga existente, pues no parece que se añadieran fundentes. Ello explica la escasez e incluso inexistencia de escorias en yacimientos meticulosamente excavados como Almizaraque o Llanete de los Moros. Dichas escorias, cuando existen, suelen arrastrar mucho cobre y/o mineral, siendo más propio hablar de conglomerados de horno, es decir, masas compuestas por gotas de metal, mineral parcialmente reducido y combustible a medio quemar, material perfectamente coherente con el primitivismo de estos procesos metalúrgicos. Lo normal es que el material escoriáceo obtenido al final de la hornada fuera machacado finamente para recuperar la mayor cantidad posible de cobre y minerales útiles, razón por la cual no se han conservado fragmentos de escorias de tamaño apreciable.

Una característica muy común de las escoriaciones de las vasijas-horno es su acusado ferromagnetismo. Significa que gran parte del hierro presente en las mismas se halla en forma de magnetita, mineral que se produce por oxidación del óxido ferroso existente en la ganga o en la pasta cerámica; su presencia indica que las condiciones reductoras en el interior de la vasija-horno eran poco estrictas, lo cual concuerda con el hecho de ser vasijas de formas muy abiertas (Montero, 1994: 228, fig. 17) cuyo ambiente reductor es difícil de controlar. Formas abiertas que además inciden en una mayor oxigenación y, por tanto, dificultan la conversión de los óxidos a metal.

La tecnología de los hornos en forma de vasija, detectada hasta ahora en la región de Madrid (Rovira, 1989; Rovira y Montero, 1994) y en el Sureste (Montero, 1994) tiene una distribución geográfica mucho mayor, como muestra

T. P., 53, n. ${ }^{\circ} 1,1996$ 


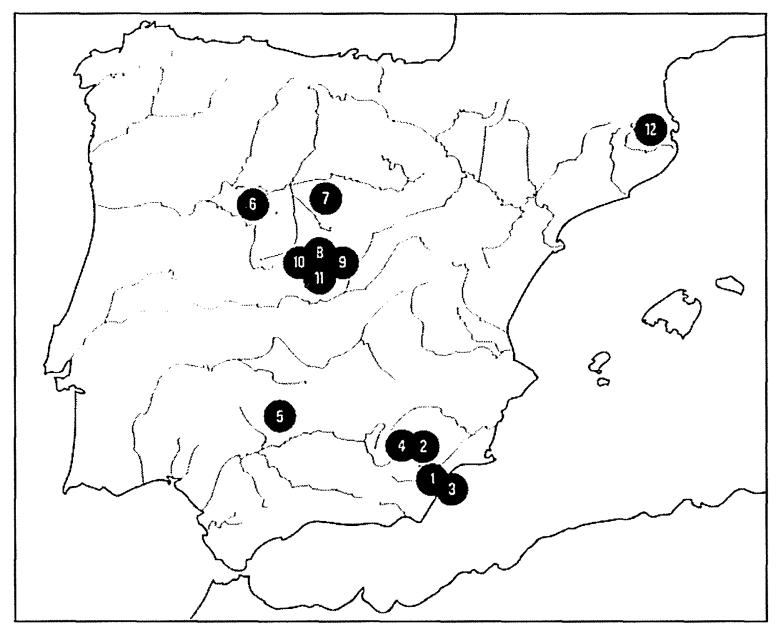

Fig. 1 Distribución de yacimientos con tecnología de vasijas-horno analizadas correspondientes al Calcolítico y Bronce Antiguo.

1. Almizaraque (Cuevas del Almanzora, Almería), 2. Cerro del Prado (Sierra de Baza, Almería), 3. Cerro Virtud-Herrerías (Cuevas del Almanzora, Almería), 4. Los Cortijillos (Sierra de Baza, Granada), 5. Llanete de los Moros (Montoro, Córdoba), 6. La Alameda (Peleagonzalo, Zamora), 7. Cueva de la Vaquera (Losana de Pirón, Segovia), 8. Arenero de Soto de Perales del Río (Getafe, Madrid), 9. El Ventorro (Villaverde, Madrid), 10. Yacimiento $\mathrm{n}^{\circ} 4$ (Villaviciosa de Odón, Madrid), 11. Yacimiento $n^{\circ}$ 35/40 (Carabaña, Madrid), 12. Bauma del Serrat del Pont (Tortellá, Gerona).

la figura 1, siendo probablemente un método generalizado en la toda la Península Ibérica durante el Calcolítico y el Bronce Antiguo.

\subsection{Bronce Medio}

A tenor de lo publicado también existe un elevado número de hallazgos de hornos de reducción y fundición en la Península Ibérica durante el Bronce Medio. Tres de los hallazgos presentados son estructuras cupulares: E1 Argar, Peña de Sax y Mas de Menente. El horno de El Argar fue señalado por Lull (1983: 254) al encontrarse varios crisoles y moldes en un espacio redondeado que al parecer estaba cubierto con una tosca bóveda de piedra y tierra. Similar es el apunte sobre el horno de Peña de Sax, donde únicamente se menciona el hallazgo de una estructura circular cubierta por una cúpula o bóveda (López Mira y Ortega, 1991: 38). Estos dos inciertos ejemplos destacan aún más al compararlos con el horno del yacimiento de Mas de Menente (Ponsell, 1926: 8; Aparicio, 1976: 47 y 194) que ya fue señalado anteriormente al hacer referencia a otros hornos de reconstrucción similar como fueron el de Almizaraque y el Cerro de las Canteras. Son hornos abovedados construidos con arcos de arcilla que han servido como modelo a seguir en una serie de reconstrucciones de difícil realidad.

En cuanto a las referencias al horno de fundición en el yacimiento murciano del Cerro de la Campana se limita a su única mención (Martínez Peñarroya y Sánchez Meseguer, 1988: 296), y los hornos albacetenses de la Morra de la Casa de los Árboles se basan en el hallazgo antiguo de un conglomerado de mineral de cobre (Sánchez Jiménez, 1947: 80-81) y, aunque no se describe estructura de fundición alguna, indican un proceso de fundición muy primitivo basado, según indicios, en hornos-vasija.

Tan sólo los pequeños pozos y construcciones de La Bastida de Totana (Inchaurrandieta, 1869: 349), Peñalosa (Contreras, Nocete y Sánchez Ruiz, 1987: 349-351) y La Horna (Hernández Pérez, 1988: 20, 29-31), algunos de ellos con adherencias o gotas de metal en su interior, podrían ser partes residuales de hornos excavados, pero desgraciadamente las descripciones son sumarias.

En un contexto singularizado por la falta de estructuras claras de fundición despunta el hecho de que los hallazgos mejor conocidos sean nuevamente, las vasijas-horno (Fig. 2) incidiendo a su vez en una tecnología metalúrgica de producción primaria bastante sencilla (véanse los análisis en la tabla 2).

Al igual que en el período precedente, la obtención de cobre se llevaba a cabo a partir de minerales oxídicos (Lám. II) de composición variable y con las mismas características anteriormente señaladas, es decir, formación de minerales parcialmente reducidos, no utilización de fundentes apropiados y condiciones excesivamente oxidantes, con la consiguiente formación de estructuras ferromagnéticas. Sin embargo, en este momento se dan dos novedades significativas; por un lado, la utilización de vasi- 


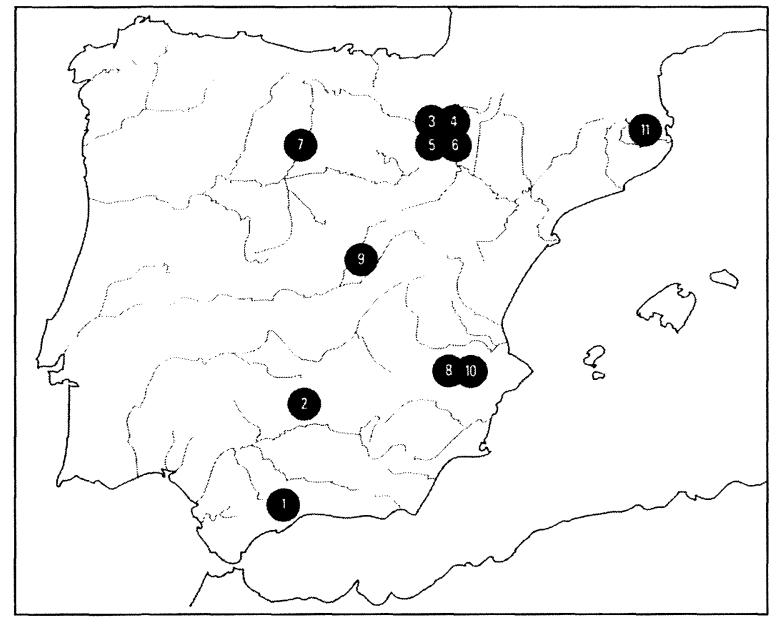

Fig. 2. Distribución de yacimientos con tecnología de vasijas-horno analizadas durante el Bronce Medio. 1. Acinipo (Ronda, Málaga), 2. Llanete de los Moros (Montoro, Córdoba), 3. Monte Aguilar I (Bárdenas Reales, Navarra), 4. Monte Aguilar II (Bárdenas Reales, Navarra), 5. Puy Águila II (Bárdenas Reales, Navarra), 6. Valdenovillas II (Bárdenas Reales, Navarra), 7. Cueva Rubia (Villaescusa de las Torres, Palencia), 8. El Acequión (Albacete), 9. Loma del Lomo (Cogolludo, Guadalajara), 10. Morra del Quintanar (Munera, Albacete), 11. Bauma del Serrat del Pont (Tortellá, Gerona).

jas-horno para la obtención de plomo como demuestra una cerámica de Acinipo y por otro, la producción de aleaciones cobre-estaño. En el

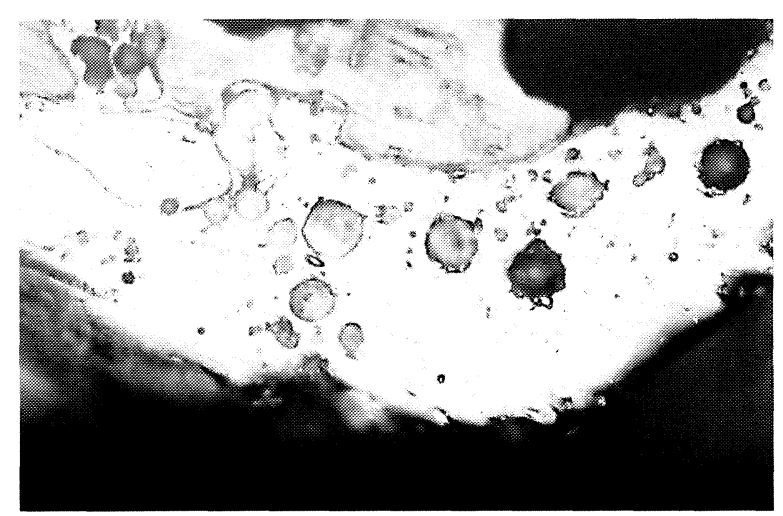

Lám. II. Microfotografía de la sección de la vasija-horno PA6326 de la Bauma del Serrat. Obsérvese el aspecto poroso de la escoriación, compuesta principalmente de óxido cuproso fundido en cuyo seno se alojan numerosos glóbulos blancos de cobre. $200 x$. primer caso, la escasa tasa de plata en la adherencia de Acinipo desestima la posibilidad de que se trate de un fragmento de copela siendo más razonable pensar en una producción de plomo bruto. En efecto, la proporción plomo/plata es del 99,35/0,145, un plomo argentífero del que se podrían obtener unos 150 grs. de plata por cada $100 \mathrm{~kg}$. de plomo copelado, proporción que según otros análisis no tendría interés ni siquiera en época romana. En cualquier caso, es el único ejemplo que hemos tenido ocasión de estudiar y que convendrá en el futuro poner en relación con los fragmentos de plomo metálico encontrados por los Siret (1890: 245) en una casa argárica de El Oficio o con las posibles escorias de producción de plomo-plata de la necrópolis de La Parrita (Pérez Macías y Frías, 1989: 13-14). En cuanto

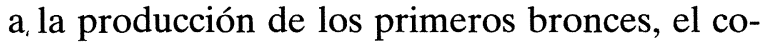
tejo de datos de los análisis de los vasos de Monte Aguilar I con los análisis de minerales del mismo yacimiento evidencia la preparación de bronce por primera vez en España mediante la reducción directa de una mezcla de minerales independientes de cobre y estaño. Debido a que la morfología de estas vasijas no parece cambiar, persisten los problemas para conseguir las condiciones reductoras adecuadas, $y$ que la reducción de la casiterita (óxido de estaño) requiere un ambiente reductor más estricto, son razones que llevan a suponer que la reducción se conseguía a base de quemar mucho carbón para conseguir así el monóxido de carbono necesario.

\subsection{Bronce Final}

El número de hallazgos durante el Bronce Final es sumamente parco aunque existen algunas referencias. En Corta del Lago (Blanco y Rothenberg, 1981: 104-107) y El Trastejón (Hurtado y García Sanjuán, 1994, passim) se basan únicamente en indicios como son la presencia de trozos de arcilla quemada, y aunque en Corta del Lago presentan escorias adheridas, en ningún caso posibilitan su reconstrucción. Las referencias de los hornos del Cabezo de Monleón, con supuestas bóvedas (Beltrán y Álvarez, 1987: 64-65; 1992-93: 66), Monte de la

T. P., 53, n. ${ }^{\circ} 1,1996$ 


\begin{tabular}{|c|c|c|c|c|c|c|c|c|c|c|}
\hline Análisis & Yacimiento & $\mathrm{Cu}$ & $\mathrm{Fe}$ & As & $\mathrm{Sb}$ & $\mathrm{Sn}$ & $\mathrm{Pb}$ & $\mathrm{Ag}$ & $\mathrm{Ni}$ & $\mathrm{Zn}$ \\
\hline PA6521 & Acinipo, Ronda (Málaga) & det & det & & det & & & & & \\
\hline PA6532 & Acinipo, Ronda (Málaga) & det & det & det & det & & & det & & \\
\hline PA6534 & Acinipo, Ronda (Málaga) & det & det & det & det & & & & & \\
\hline PA6535 & Acinipo, Ronda (Málaga) & $\operatorname{det}$ & det & det & det & & & & & \\
\hline PA6533 & Acinipo, Ronda (Málaga) & 0.50 & - & nd & nd & nd & 99.35 & 0.141 & - & nd \\
\hline PA5069 & Llanete de los Moros, Montoro (Córdoba) & $34^{\prime} 70$ & $38 ’ 15$ & $26 ’ 38$ & $0 ’ 137$ & $0 ’ 462$ & nd & 0’072 & nd & nd \\
\hline PA4705A & Monte Aguilar I, Bárdenas Reales (Navarra) & $89 ’ 18$ & 374 & $0 ’ 85$ & $3 ' 59$ & 2'17 & nd & $0 ’ 452$ & nd & nd \\
\hline PA4705B & Monte Aguilar I, Bárdenas Reales (Navarra) & $90 ’ 10$ & 5,96 & $1 ' 10$ & $1 ’ 21$ & $1 ' 10$ & nd & $0 ’ 275$ & nd & nd \\
\hline PA4713 & Monte Aguilar I, Bárdenas Reales (Navarra) & $48 ’ 50$ & $1 ’ 17$ & nd & nd & $50 ’ 28$ & nd & nd & nd & nd \\
\hline PA4854 & Monte Aguilar I, Bárdenas Reales (Navarra) & $94 ’ 94$ & $2 ’ 57$ & $2 ’ 29$ & 0’103 & 0’096 & nd & nd & nd & nd \\
\hline PA4720 & Puy Águila II, Bárdenas Reales (Navarra) & $97 ' 50$ & $2 ’ 38$ & nd & 0’044 & 0’078 & nd & 0’005 & nd & nd \\
\hline PA4721 & Valdenovillas II, Bárdenas Reales (Navarra) & $95^{\prime} 80$ & $2 ’ 98$ & nd & 0’323 & 0’861 & nd & 0’010 & nd & nd \\
\hline PA2313 & Cueva Rubia, Villaescusa (Palencia) & $97^{\prime} 42$ & $1^{\prime} 84$ & nd & 0’011 & 0’032 & nd & nd & - & nd \\
\hline PA2314 & Cueva Rubia, Villaescusa (Palencia) & $98 ' 55$ & $0 ’ 83$ & nd & 0’019 & 0'131 & nd & nd & - & nd \\
\hline PA2315 & Cueva Rubia, Villaescusa (Palencia) & $88 ’ 09$ & $4 ’ 38$ & 573 & 0’200 & $1 ’ 41$ & nd & nd & - & nd \\
\hline PA2306 & El Acequión, Albacete & $82 ' 83$ & $14 ' 12$ & $\operatorname{tr}$ & $\operatorname{tr}$ & nd & nd & nd & nd & nd \\
\hline PA4341A & Loma del Lomo, Cogolludo (Guadalajara) & det & det & det & ، det & & & & & \\
\hline PA5354 & Loma del Lomo, Cogolludo (Guadalajara) & $\operatorname{tr}$ & - & nd & $\operatorname{tr}$ & $\operatorname{tr}$ & nd & nd & - & nd \\
\hline PA0973 & Morra del Quintanar, Munera (Albacete) & $92{ }^{\prime} 69$ & $4 ' 55$ & $1 ’ 99$ & 0’051 & nd & $0{ }^{\prime} 27$ & 0’012 & - & nd \\
\hline PA6326 & Bauma del Serrat, Tortellá (Gerona) & $94 ' 65$ & nd & nd & $0 ’ 652$ & $4^{\prime} 64$ & nd & 0’053 & nd & nd \\
\hline PA6327 & Bauma del Serrat, Tortellá (Gerona) & $99 ’ 20$ & nd & nd & 0’054 & $0 ’ 55$ & $\operatorname{tr}$ & 0’055 & $\operatorname{tr}$ & nd \\
\hline
\end{tabular}

Tabla 2. Análisis elemental de escoriaciones en vasijas-horno del Bronce Medio, despreciando la ganga (\% en peso).

Cantabria (Luengo, 1941: 126-127) y Genó (Maya, 1982: 159-160) son igualmente escasas e imprecisas. Tan sólo el horno localizado en el interior de una vivienda de Peña Negra I responde al prototipo de estructura buscada. Se trata de un pequeño horno de fundición, formado por un anillo de arcilla de $60 \mathrm{~cm}$ de diámetro con un hueco interior de $20 \mathrm{~cm}$ (González Prats, 1993: 23-24). Sin embargo, aquí también surgen algunos problemas. Aparte del hecho de que la estructura mencionada no presente indicio alguno de escorias, material rubefactado, etc. el análisis de numerosos restos de vasijas-horno de este yacimiento por parte del Proyecto de Arqueometalurgia evidencia una tecnología primitiva de producción basada, una vez más, en las vasijas como receptáculos para la reducción de minerales. La falta de escorias de sangrado en el yacimiento (las escorias de este poblado son conglomerados) aboga igualmente por esta interpretación. Tal vez el repeti- do hoyo de Peña Negra fuese un horno de fusión de metal. Sin embargo, recientemente se ha señalado (Ruiz-Gálvez, 1993: 53) que la colada no se haría en esta estructura sino en el exterior de la vivienda, lugar donde se acumulan los moldes y otros elementos relacionados con la producción metalúrgica por lo que se deja sin explicación cuál fue entonces la funcionalidad del supuesto horno pues la unicidad de vasijas-horno en el yacimiento y la falta de fragmentos de revestimiento descartan su vinculación directa con la reducción de minerales.

Los análisis de materiales del Bronce Final (Tabla 3) certifican en los dos casos casos la utilización de vasijas para la obtención de cobres y bronces (Lám. III). La escasa cantidad de hierro presente indica la ausencia de fundentes férricos, con la consiguiente dificultad de formación de verdaderas escorias de bajo punto de fusión. La reducción (con grandes pérdidas de mineral) debía conseguirse a expensas de un 


\begin{tabular}{|c|c|c|c|c|c|c|c|c|c|c|}
\hline Análisis & Yacimiento & $\mathrm{Cu}$ & $\mathrm{Fe}$ & As & $\mathrm{Sb}$ & $\mathrm{Sn}$ & $\mathrm{Pb}$ & $\mathrm{Ag}$ & $\mathrm{Ni}$ & $\mathrm{Zn}$ \\
\hline PA6522 & Ronda (Málaga) & $91 ’ 06$ & $8{ }^{\prime} 72$ & nd & 0’048 & 0’147 & nd & $\operatorname{tr}$ & nd & nd \\
\hline PA6529 & Ronda (Málaga) & $55 ’ 92$ & $8 ' 39$ & nd & 0’125 & $22 ' 53$ & $12^{\prime} 42$ & 0’015 & nd & nd \\
\hline PA6531 & Ronda (Málaga) & $\operatorname{det}$ & $\operatorname{det}$ & det & & & & & & \\
\hline PA6537 & Ronda (Málaga) & $33 ’ 22$ & $2^{\prime} 01$ & nd & nd & $588^{\prime} 40$ & 6’08 & nd & nd & nd \\
\hline PA0306A & Peña Negra, Crevillente (Alicante) & $91 ’ 79$ & $0 ’ 26$ & nd & 0’023 & $2{ }^{\prime} 82$ & $0 ’ 48$ & nd & nd & $0 ’ 75$ \\
\hline PA0306AD & Peña Negra, Crevillente (Alicante) & 91’91 & $0 ’ 15$ & nd & 0’135 & 2’43 & $0 ’ 53$ & 0’009 & $0 ’ 18$ & $0 ’ 81$ \\
\hline PA0306AE & Peña Negra, Crevillente (Alicante) & $58 ’ 21$ & $4^{\prime} 03$ & $1 ' 16$ & 0'790 & $322^{\prime} 82$ & $1 ’ 49$ & 0’004 & 0,36 & nd \\
\hline PA0306C & Peña Negra, Crevillente (Alicante) & $20 ’ 49$ & $0 ’ 37$ & 2'66 & 0’864 & 0’77 & $69^{\prime} 66$ & nd & $0 ’ 21$ & nd \\
\hline PA0306H & Peña Negra, Crevillente (Alicante) & 75,27 & $1 ' 29$ & nd & 0’338 & $199^{\prime} 90$ & 1'34 & 0’007 & $0 ’ 31$ & nd \\
\hline PA0306I & Peña Negra, Crevillente (Alicante) & $91 ’ 69$ & $0 ’ 33$ & $0 ’ 65$ & 0’093 & $1 ’ 87$ & $2 ’ 24$ & 0’010 & $0 ’ 86$ & nd \\
\hline PA0306L & Peña Negra, Crevillente (Alicante) & $69 ’ 25$ & $1^{\prime} 63$ & $0 ’ 37$ & $0 ’ 425$ & $25 ’ 11$ & $1 ’ 22$ & 0’004 & $0 ’ 23$ & nd \\
\hline PA0306M & Peña Negra, Crevillente (Alicante) & $69 ’ 31$ & $1 ' 10$ & $0 ’ 99$ & 0’888 & $19^{\prime} 92$ & $3{ }^{\prime} 44$ & 0’017 & $0 ’ 30$ & nd \\
\hline PA0306Q & Peña Negra, Crevillente (Alicante) & $67 ’ 62$ & $1 ’ 28$ & $1 ’ 06$ & 1’01 & $18^{\prime} 69$ & $5 ’ 49$ & 0’022 & $0 ’ 26$ & nd \\
\hline PA0306S & Peña Negra, Crevillente (Alicante) & $12^{\prime} 03$ & $0 ’ 33$ & $2^{\prime} 18$ & 0'524 & $0 ’ 771$ & $800^{\prime} 90$ & nd & $0 ’ 38$ & nd \\
\hline PA0306T & Peña Negra, Crevillente (Alicante) & 77’11 & $0 ’ 41$ & $0 ’ 67$ & 0’304 & $17 ’ 00$ & 0’61 & 0’004 & $0 ’ 20$ & nd \\
\hline PA0306W & Peña Negra, Crevillente (Alicante) & 93’07 & $0 ' 17$ & nd & 0’104 & $0^{\prime} 458$ & 1,57 & 0’004 & $0 ’ 31$ & nd \\
\hline PA0306X & Peña Negra, Crevillente (Alicante) & $80 ’ 64$ & $0 ’ 63$ & $0 ’ 41$ & $0 ’ 345$ & $15^{\prime} 62$ & $0 ’ 53$ & 0’010 & $0 ’ 36$ & $0 ’ 38$ \\
\hline PA0306Y & Peña Negra, Crevillente (Alicante) & $91 ’ 07$ & 5,26 & $0 ' 16$ & $0 ’ 054$ & $0^{\prime} 467$ & 0'94 & 0’003 & 0,52 & nd \\
\hline PA0306Z & Peña Negra, Crevillente (Alicante) & $73 ’ 74$ & $1 ’ 24$ & $0 ’ 58$ & 0’304 & $21^{\prime} 64$ & $0 ’ 71$ & 0’003 & $0 ’ 41$ & 0'31 \\
\hline PA0353 & Peña Negra, Crevillente (Alicante) & 89'17 & 1'86 & nd & 0’077 & 3'51 & nd & 0’017 & 0'78 & nd \\
\hline
\end{tabular}

Tabla 3. Análisis elemental de las escoriaciones en vasijas-horno del'Bronce Final, despreciando la ganga (\% en peso).

elevado consumo de carbón. En el caso de Peña Negra los análisis realizados también a minerales y restos de metal bruto indican que el proceso de reducción llevado a cabo en las vasijas implicaba pérdidas significativas de estaño, lo que explica por qué muchos de los bronces de Peña Negra, obtenidos por reducción directa de minerales de cobre y estaño, son pobres en este último metal. Esta observa-

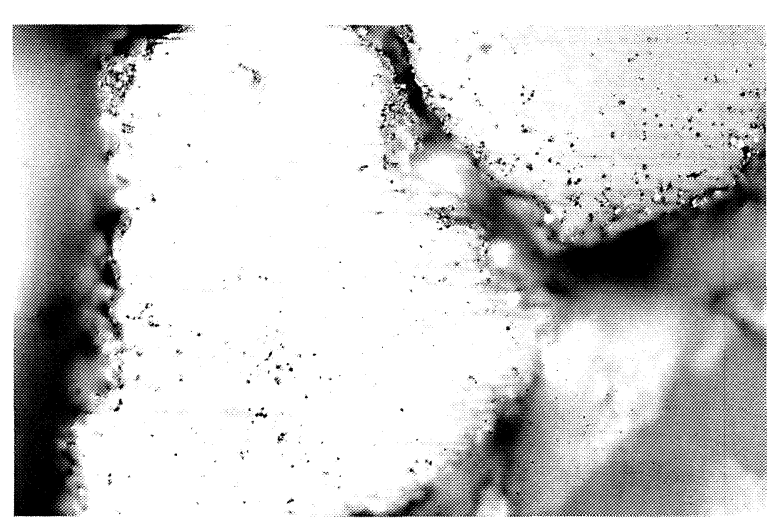

Lám. III. Microfotografía de la sección de la vasija-horno PA6537 de Ronda. El campo está ocupado por dos granos de óxido cuproso conteniendo inclusiones esféricas de metal. 500x. ción es sumamente sugestiva ya que indica que la existencia de tasas bajas de estaño en los bronces no es sólo consecuencia de la escasa disponibilidad de materia prima (explicación a la que se recurre frecuentemente y que ha sido también empleada para explicar el fenómeno de la adición de plomo a los bronces) sino de la tecnología metalúrgica empleada. En este caso parece claro que no es un problema de abastecimiento de minerales de estaño sino de una deficiente tecnología de horno. De la lectura de éstos y otros ejemplos, se observa que en el Bronce Final todavía no se domina la metalurgia productiva con ayuda de fundentes y todo el volumen de cobre o bronce local se consigue a base de multiplicar la pequeña producción de la vasija-horno.

\subsection{Edad del Hierro}

Las referencias sobre hallazgos de hornos y otros restos de fundición durante toda la Edad del Hierro son numerosísimas si bien la inmensa mayoría son descripciones confusas y al carecer de estudios metalúrgicos no se pueden especificar correctamente. El trabajo de cobre y 


\begin{tabular}{|c|c|c|c|c|c|c|c|c|c|c|}
\hline Análisis & Yacimiento & $\mathrm{Cu}$ & $\mathrm{Fe}$ & As & $\mathrm{Sb}$ & Sn & $\mathrm{Pb}$ & $\mathrm{Ag}$ & $\mathrm{Ni}$ & $\mathrm{Zn}$ \\
\hline AA1262A & Medellín (Badajoz) & $16^{\prime} 63$ & $18^{\prime} 58$ & $\operatorname{tr}$ & $0 ’ 227$ & 33’90 & $30 ’ 70$ & 0’022 & - & nd \\
\hline AA1262B & Medellín (Badajoz) & $15 ’ 24$ & 3’11 & $0 ’ 31$ & 0’085 & $30^{\prime} 44$ & $49 ’ 94$ & $\operatorname{tr}$ & - & nd \\
\hline AA1263A & Medellín (Badajoz) & $25{ }^{\prime} 80$ & 4’34 & $2 ’ 74$ & $0 ’ 495$ & $13 ’ 38$ & $52 ’ 64$ & nd & - & nd \\
\hline AA1263B & Medellín (Badajoz) & $21 ’ 41$ & $10 ’ 80$ & $2 ’ 27$ & 0’181 & $17 ' 54$ & $47 ’ 21$ & 0’014 & - & nd \\
\hline PA3671 & Campa Torres, Gijón (Asturias) & $24 ’ 91$ & $8 ’ 35$ & nd & 0’239 & $60 ’ 19$ & $4 ' 79$ & 0’018 & - & nd \\
\hline PA3687 & Campa Torres, Gijón (Asturias) & $24 ’ 93$ & $4^{\prime} 41$ & nd & 0’129 & $67 ' 53$ & 2’94 & 0’018 & - & nd \\
\hline PA3688 & Campa Torres, Gijón (Asturias) & $422^{\prime} 03$ & 3’82 & nd & 0’391 & $47^{\prime} 67$ & $6 ’ 02$ & 0’070 & - & nd \\
\hline PA3335 & El Castrelín, San Juan de P. (León) & $70 ` 43$ & 6’18 & $8 ’ 06$ & 3’332 & 0’681 & $2 ’ 47$ & 0’091 & $6{ }^{\prime} 57$ & nd \\
\hline PA3336 & El Castrelín, San Juan de P. (León) & $2 ’ 20$ & $72{ }^{\prime} 51$ & nd & $0 ’ 289$ & $1 ' 18$ & $18^{\prime} 23$ & $5^{\prime} 60$ & nd & nd \\
\hline PA3360 & El Castrelín, San Juan de P. (León) & $18^{\prime} 10$ & $20 ’ 35$ & nd & $0 ’ 228$ & $17 ’ 66$ & $13 ’ 55$ & $25{ }^{\prime} 49$ & nd & nd \\
\hline PA3365 & El Castrelín, San Juan de P. (León) & $199^{\prime} 81$ & $1 ' 13$ & nd & nd & nd & 63’34 & $15{ }^{\prime} 34$ & $0 ’ 35$ & nd \\
\hline PA3366 & El Castrelín, San Juan de P. (León) & $14^{\prime} 76$ & $2 ’ 25$ & nd & nd & nd & $75 ’ 20$ & 6’96 & $0 ’ 82$ & nd \\
\hline PA3367 & El Castrelín, San Juan de P. (León) & 33 '03 & $0 ’ 77$ & nd & nd & nd & $311^{\prime} 01$ & $33 ’ 96$ & $0 ’ 45$ & nd \\
\hline PA3331A & El Castrelín, San Juan de P. (León) & $13^{\prime} 75$ & 9'46 & nd & 1'17 & $24 ’ 30$ & $48^{\prime} 57$ & nd & nd & nd \\
\hline PA3331B & El Castrelín, San Juan de P. (León) & $12 ' 50$ & $388^{\prime} 90$ & nd & $0 ’ 579$ & $20 ’ 78$ & $222^{\prime} 72$ & nd & nd & nd \\
\hline PA3742A & El Castrelín, San Juan de P. (León) & $50 ’ 94$ & 2'54 & $1 ' 18$ & 2’37 & $222^{\prime} 50$ & 8’67 & 0’027 & $11^{\prime} 77$ & nd \\
\hline PA3742B & El Castrelín, San Juan de P. (León) & $35 ’ 66$ & $28{ }^{\prime} 2$ & $2^{\prime} 18$ & $0{ }^{\prime} 434$ & $14 ’ 06$ & $15^{\prime} 51$ & $00^{\prime} 051$ & 3'85 & nd \\
\hline PA2463 & Castro de Barahones, Valdegama (Palencia) & $73 ’ 05$ & $0 ’ 03$ & nd & nd & $22{ }^{\prime} 45$ & 3'68 & nd & - & nd \\
\hline PA2462 & Castro de Barahones, Valdegama (Palencia) & $82 ’ 71$ & $0 ’ 41$ & $3 ’ 53$ & $0 ’ 22$ & 6’16 & 675 & $0 ’ 110$ & - & nd \\
\hline PA2176 & Castro de Hinojo, Caserío de H. (León) & $80 ’ 85$ & nd & nd & nd & $13^{\prime} 56$ & $5^{\prime} 31$ & nd & nd & nd \\
\hline PA4421 & Castro de Pedredo (León) & $25 ’ 90$ & $6 ’ 52$ & nd & $0 ’ 36$ & $26^{\prime} 69$ & $37 ’ 66$ & 0’071 & nd & nd \\
\hline PA4422 & Castro de Pedredo (León) & $533^{\prime} 38$ & $3 ’ 00$ & nd & 0'14 & $19{ }^{\prime} 18$ & $233^{\prime} 79$ & 0’037 & $0 ’ 46$ & nd \\
\hline PA4423 & Castro de Pedredo (León) & $\operatorname{det}$ & det & det & & & & & & \\
\hline PA0467A1 & La Corona de Corporales, Truchas (León) & $51 ’ 95$ & 7'55 & $0 ’ 41$ & 0’596 & 22’18 & $15{ }^{\prime} 89$ & 0’034 & - & nd \\
\hline PA0453B & La Corona de Corporales, Truchas (León) & $15^{\prime} 44$ & $35{ }^{\prime} 30$ & nd & $0 ’ 290$ & $43^{\prime} 48$ & 2’58 & nd & nd & nd \\
\hline IR5132-3 & Illa d'en Reixac, Ullastret (Gerona) & $45^{\prime} 07$ & 3'87 & nd & nd & $46 ’ 38$ & 4'14 & nd & 0'19 & nd \\
\hline PA3373 & Illa d'en Reixac, Ullastret (Gerona) & $44^{\prime} 74$ & 2'69 & nd & nd & $48{ }^{\prime} 35$ & $4^{\prime} 13$ & nd & nd & nd \\
\hline PA3376 & Illa d'en Reixac, Ullastret (Gerona) & $322^{\prime} 83$ & $10 ' 14$ & nd & 0’076 & $56 ' 28$ & 0,67 & nd & nd & nd \\
\hline PA3382 & Illa d'en Reixac, Ullastret (Gerona) & $89 ’ 31$ & 679 & nd & $0 ’ 223$ & 3’57 & $0 ’ 06$ & 0’045 & - & nd \\
\hline
\end{tabular}

Tabla 4. Análisis elemental de las adherencias en vasijas-horno de la Edad del Hierro, despreciando la ganga (\% en peso).

bronce queda, a juzgar por los hallazgos, relegado a un segundo término ya que gran parte de la información refiere a hornos siderúrgicos o bien a hornos para la obtención de plata, éstos últimos en yacimientos orientalizantes.

Existen sin embargo, referencias a hornos de procesado de cobre y bronce en algunos yacimientos de la Segunda Edad del Hierro. En la zona de hábitat del asentamiento indígena prerromano de La Campa Torres (Gijón) aparecieron numerosos elementos relacionados con la metalurgia del bronce (Maya et alii, 1993: 8594) entre ellos vestigios de zonas de fundición de crisoles y vasijas-hornos que parece ser el tipo de horno empleado en éste y otros yacimientos como los leoneses de El Castrelín
(Fernández-Posse et alii, 1993, passim) y La Corona de Corporales (Fernández-Posse et alii, 1993, passim). De la bibliografía se infiere que la vasija-horno se combina con hornos de tipo excavado en el yacimiento gerundense de Illa d'en Reixac (Rovira i Hortalà, 1993: 65-149).

Analíticamente hemos estudiado materiales cerámicos correspondientes a los yacimientos de la tabla 4. El proceso de reducción de cobre y bronce va a seguir prácticamente hasta época romana funcionando a base de la multiplicación de la vasija-horno (Fig. 3). Los análisis de materiales de yacimientos como Medellín indican la producción de bronces ternarios mediante la reducción conjunta de minerales de cobre, estaño y plomo. La dinámica de fundición 


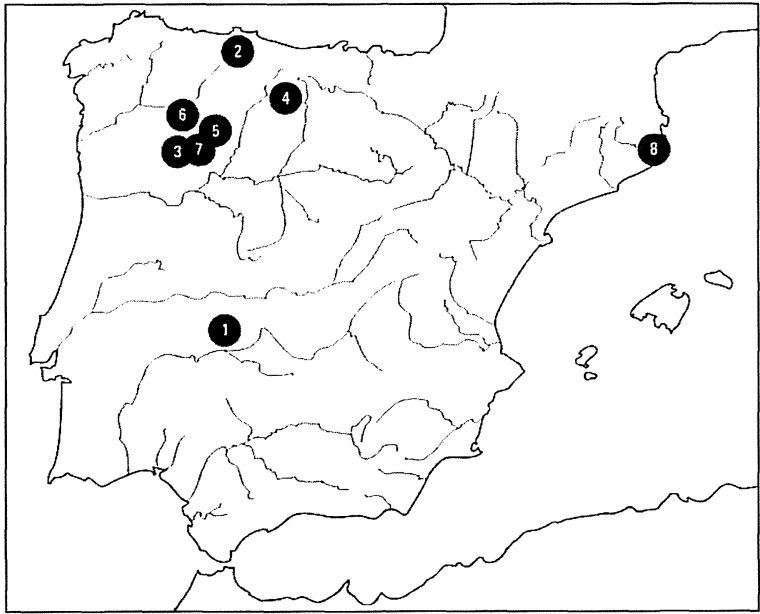

Fig. 3. Distribución espacial de yacimientos con tecnología de vasijas-horno analizadas durante la Edad del Hierro. 1. Medellín (Badajoz), 2. Campa Torres (Gijón, Asturias), 3. El Castrelín (San Juan de Paluezas), 4. Castro de Barahones (Valdegama, Palencia), 5. Castro de Hinojo (Caserío de Hinojo, León), 6. Castro de Pedredo (León), 7. Corona de Corporales (Truchas, León), 8. Illa d'en Reixac (Ullastret, Gerona).

sigue siendo la misma: ambientes excesivamente oxidantes que forman escoriaciones ferromagnéticas, con grandes pérdidas de metal (Lám. IV), desperdicio de minerales y ausencia o uso inapropiado de fundentes. En efecto, las escorias de cobre o bronce son, en general, de mala calidad (no existen escorias de sangrado), muy silicatadas y poco ferruginosas debido a que no se añaden fundentes o se añade arena, demostrando un escaso conocimiento de la composición de los minerales y de los principios metalúrgicos de la formación de escoria. Son muy pocas las evidencias de hornos de otro tipo, y siempre extraídas de fragmentos de revestimiento, no de estructuras claramente atribuibles a hornos por el registro arqueológico. Encontramos sin embargo los primeros indicios del uso de hornos más complejos a través del hallazgo de revestimientos en Capote, El Castrelín y Piedra de Ángeles (Tabla 5), relacionados con la obtención de bronces ternarios en los dos primeros ejemplos. Quizá lo más sorprendente es la utilización conjunta de la vasija y del horno excavado como se observa en El Castrelín y que podría venir condiciona-

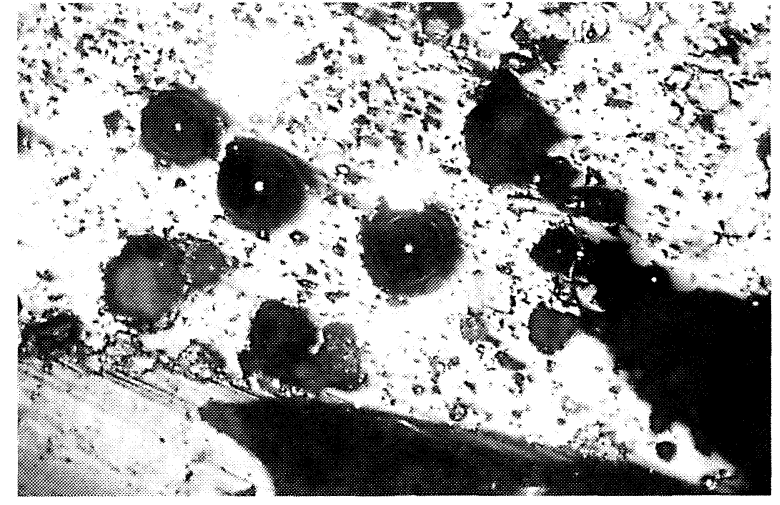

Lám. IV. Microfotografía de la sección de la vasija-horno PA3745 de El Castrelín. La escoriación, muy porosa, contiene abundantes esferas de metal y óxidos metálicos. $35 \mathrm{x}$.

da por distintos requerimientos de metal en un momento dado. En todo caso, ambos son procedimientos muy simples.

\section{CONCLUSIONES}

Sin lugar a dudas la primera conclusión que se extrae tras la consulta atenta a la bibliografía y al análisis de materiales es el primitivismo de la tecnología de fundición en toda la Pre y Protohistoria peninsular. Es una tecnología que descansa hasta la Edad del Hierro inclusive, en un tipo de horno preferente: la vasija cerámica. Somos conscientes de que la naturaleza cerámica de estas vasijas hace que, como material inorgánico, sea muy estable y por tanto se conserve bien durante milenios, lo que podría parecer en un principio una desvirtualización de los tipos y variedades de hornos utilizados en la Prehistoria peninsular. Sin embargo, aunque las posibles estructuras de hornos excavadas en el suelo o con muretes de barro son mucho más perecederas, lo cierto es que dichos hornos dejarían algún tipo de residuo pirometalúrgico que por el momento no ha sido hallado.

Las pruebas analíticas indican que el ambiente reductor en el interior de las vasijas no era muy estricto, pues se forman frecuentemente óxidos ferromagnéticos. Es lógico que así sea en unos recipientes muy abiertos y quizá exce-

T. P., 53, n. ${ }^{\circ} 1,1996$ 


\begin{tabular}{|l|l|c|c|c|c|c|c|c|c|c|}
\hline Análisis & Yacimiento & $\mathrm{Cu}$ & $\mathrm{Fe}$ & $\mathrm{As}$ & $\mathrm{Sb}$ & $\mathrm{Sn}$ & $\mathrm{Pb}$ & $\mathrm{Ag}$ & $\mathrm{Ni}$ & $\mathrm{Zn}$ \\
\hline PA6741A & Capote (Badajoz) & $74^{\prime} 87$ & $1^{\prime} 50$ & $\mathrm{nd}$ & $0^{\prime} 067$ & $18^{\prime} 00$ & $5^{\prime} 25$ & $0^{\prime} 006$ & nd & nd \\
PA3363 & El Castrelín, San Juan de P. (León) & $29^{\prime}, 6$ & $30^{\prime} 55$ & $1^{\prime} 82$ & $1^{\prime} 71$ & $25^{\prime} 21$ & $9^{\prime} 14$ & nd & $1^{\prime} 11$ & nd \\
PA2908 & Piedra de Ángeles, Titaguas (Valencia) & $47^{\prime} 86$ & $2^{\prime} 47$ & nd & $0^{\prime} 748$ & $48^{\prime} 46$ & nd & nd & $0^{\prime} 27$ & nd \\
\hline
\end{tabular}

Tabla 5. Análisis elemental de revestimientos de horno (\% en peso).

sivamente ventilados. Afortunadamente la reducción de los óxidos de cobre no necesita unas condiciones reductoras pronunciadas. El metal obtenido en estos sencillos hornos se encontraba en forma de pequeños nódulos y filamentos, probablemente embebidos en una masa de minerales parcialmente reducidos y fundidos que era necesario machacar para extraerlos. También es muy probable que después de la operación fuera requisito romper la vasija pues la masa solidificaría rápidamente y quedaría adherida a las paredes y al fondo de la misma. Ello explicaría el estado fragmentario en que aparecen todas las vasijas. Ni la capacidad del horno ni las condiciones térmicas son las adecuadas para la formación de metal en bruto, lo cual concuerda con la carencia de lingotes bien definidos en las etapas más antiguas de la Edad del Bronce Europeo (Tylecote, 1976). Las porciones de cobre obtenidas eran refundidas en crisoles para formar coladas con el volumen suficiente para fabricar las piezas. Avezados metalúrgicos han fracasado en los intentos experimentales para obtener tortas grandes de metal por lo que nada tendría de particular que los metalúrgicos prehistóricos hispánicos adoptaran la vasija-horno como una forma práctica de producir metal, sin experimentar otras posibilidades.

También es característica de la vasija-horno la baja producción de escoria. Este no es un fenómeno particular de la Península Ibérica y ya había sido puesto de manifiesto para toda la Edad del Bronce del Occidente europeo por Craddock y Meeks (1987). Con nuestro trabajo confirmamos dicha apreciación, con los que coincidimos también en que las causas son el empleo de minerales de cobre con poca ganga procesados sin la ayuda de fundentes. La abundancia en la Península Ibérica de mineralizaciones de cobre a cielo abierto y la pureza de los minerales son argumentos indirectos que apoyan la adopción de la vasija-horno como método sencillo y práctico de obtención de metal sin necesidad de recurrir a procedimientos más sofisticados.

Otro hecho cierto es que la vasija-horno no fue característica sólo de la Península Ibérica como demostraron Zwicker et alii (1985). Habrá que esperar a que otros países europeos aborden trabajos sistemáticos como el que hemos iniciado para conocer mejor la extensión de esta tecnología, que quizá se encuentre más difundida de lo que en principio pudiera parecer y cuya realidad no se ha podido percibir antes debido a la errónea asunción apriorística de que la metalurgia productiva requiere hornos de cierta complejidad. Sin embargo, de lo que no cabe la menor duda es del éxito funcional de este método de obtención de metales pues en la Península Ibérica se siguió empleando sin modificaciones perceptibles a lo largo de tres milenios desde el Calcolítico antiguo hasta la romanización. No parece apreciarse aquí la evolución dada, por ejemplo, en el Valle de Timna donde desde los asentamientos calcolíticos del IV milenio a.C. hasta los de época romana se ha documentado una metalurgia extractiva basada en hornos que evolucionaron desde simples hoyos en el suelo hasta estructuras de construcción más compleja (Rothenberg, 1985 y 1990).

\section{BIBLIOGRAFÍA}

Aparicio, J. (1976): “Estudio económico y social de la Edad del Bronce Valenciano". Publicaciones del Archivo Municipal del Ayuntamiento de Valencia. Valencia. Arribas, A.; Molina, F.; Carrión, F.; Contreras, F.; Martínez, G.; Ramos, A.; SÁez, L.; Torre, F. DE LA; BLANCO, I. Y MARTíNEZ, J. (1987): "Informe preliminar de los resultados obtenidos durante la VI campaña 
de excavaciones en el poblado de los Millares (Santa Fe de Mondújar, Almería), 1985". Anuario Arqueológico de Andalucía/1985, II: 245-262.

BACHMANN, H. (1980): "Early copper smelting techniques in Sinai and in the Negev as deduced from slag investigations". En P. Craddock (ed.): Scientific Studies in Early Mining and Extractive Metallurgy. British $\mathrm{Mu}-$ seum Occasional Paper, 20. Londres: 103-134.

BeltrÁn, A. y Álvarez, A. (1987): “Una comprobación de las excavaciones del poblado del Bronce Final y de la I Edad del Hierro del cabezo de Monleón, Caspe (Zaragoza)". Museo de Zaragoza, Boletín, 6: 59-69.

BERNus, S. (1983): "Découvertes, hypothèses, reconstitution et preuves: le cuivre médiéval d'Azelik-Takedda (Niger)". En N. Échard (ed.): Métallurgies Africaines. Nouvelles contributiones. Mémoires de la Société des Africanistes, 9. París: 153-171.

Bernus, S. y ÉchaRd, N. (1985): "Metal working in the Agadez region (Niger): an ethno-archaeological approach". En P. Craddock y M. Hughes (eds.): Furnaces and Smelting Technology in Antiquity. British Museum Occasional Paper, 48. Londres: 71-80.

BlANCO, A. y RothenBerg, B. (1981): "Exploración Arqueometalúrgica de Huelva (EAH)”. Ed. Labor. Barcelona.

BRunN, A. (1993): "Experiments on Copper-Smelting at Rocca San Silvestro". En Archaeologia delle Attività Estrative e Metallurgiche. V Ciclo di Lezioni sulla Ricerca Applicata in Archeologia, settembre 1991, All'Insegna del Giglio, Firenze: 629-638.

CABrero, R. (1987): "Informe preliminar sobre las excavaciones arqueológicas realizadas en el yacimiento de Amarguillo II (Los Molares, Sevilla)". Anuario Arqueológico de Andalucía/1986, II: 180-185.

- (1990): "El poblado de la Edad del Cobre denominado Amarguillo II (Los Molares, Sevilla). Informe preliminar tras la excavación sistemática de 1987”. Anuario Arqueológico de Andalucía/1987, II: 276-277.

CARrilero, M. y SuÁrez, A. (1989-90): "Ciavieja (El Ejido, Almería): resultados obtenidos en las campañas de 1985 y 1986. El poblado de la Edad del Cobre". Cuadernos de Prehistoria de la Universidad de Granada, 14-15: 109-136.

Coghlan, H. (1975): Notes on the Prehistoric Metallurgy of Copper and Bronze in the Old World. Occasional Papers on Technology, 4. $1^{\text {a }}$ ed. 1951. Pitt Rivers Museum. Oxford.

Contreras, F.; Nocete, F. y SÁnchez Ruiz, M. (1987): "Primera campaña de excavaciones en el yacimiento de la Edad del Bronce de Peñalosa (Baños de la Encina, Jaén)". Anuario Arqueológico de Andalucía/1986, II: 342-352.

CRADDOCK, P. (1989): “The scientific investigation of early mining and smelting". En J. Henderson (ed.): Scientific analysis in archaeology and its interpretation. Oxford University Committee for Archaeology, 19. Oxford: 178-212.

Craddock, P. y MeEks, N. (1987): "Iron in ancient copper". Archaeometry, 29 (2): 187-204.

Fernández-Posse, D.; Montero, I.; SÁnChez Palencia, F.J. y Rovira, S. (1993): "Espacio y metalurgia en la cultura castreña: la zona arqueológica de las Médulas". Trabajos de Prehistoria, 50: 197-220.
Forbes, R.J. (1971): "Studies in Ancient Technology". VIII. $2^{a}$ ed. revisada. $1^{a}$ ed. 1964 . E. J. Brill. Leiden.

- (1972): "Studies in Ancient Technology", IX. 2a. ed. revisada. $1^{a}$. ed. 1964. E. J. Brill. Leiden.

Gómez RAmos, P. (1995): “La tecnología de fundición de metales en la Pre y Protohistoria de la Península Ibérica". Tesis Doctorales microfichadas de la Universidad Autónoma de Madrid. Madrid.

Gonçalves, V. (1983-1984): “Cabeço de Pé da Erra (Coruche), contribuiçao da campanha 1 (83) para o conhecimento do seu povoamento calcolítico". Clío/Arqueología, 1: 69-75.

- (1989): "Megalitismo e metalurgia no Alto Algarve Oriental. Uma aproximaçao integrada". Estudos e memórias, 2, Instituto Nacional de Investigaçao Científica. Lisboa.

GonzÁlez Prats, A. (1993): "La metalurgia del Bronce Final en el sudeste de la Península Ibérica". En R. Arana; A. M ${ }^{\text {a }}$. Muñoz; S. Ramallo. y M. Ros (eds.): "Metalurgia en la Península Ibérica durante el primer milenio a.C. Estado actual de la investigación”. Universidad de Murcia. Murcia: 19-43.

GRÉBÉNART, D. (1983): "Les métallurgies du cuivre et du fer autour d'Agadez (Niger), des origines au début de la période médiévale. Vues générales". En N. Échard (ed.): Métallurgies Africaines. Nouvelles contributiones. Memoires de la Société des Africanistes, 9. París: 109-125.

- (1988): "Les origenes de la métallurgie en Afrique Occidentale". Ed. Errance. París.

Hernández Pérez, M. (1988): "La Horna, Aspe, Vinalpó Mitjà". Memòries Arqueològiques a la Comunitat Valenciana, 1984-1985. Generalitat Valenciana. Valencia: 71-72.

Hook, D.; Freestone, I.; Meeks, N.; Craddock, P. y Moreno, O. (1991): "The early production of copperalloys in South-East Spain". En E. Pernicka y G. Wagner (eds.): Archaeometry'90. Heidelberg, 2-6 abril 1990. Berlín: 65-76.

Hurtado, V. y García Sanjuán, L. (1994): “Áreas funcionales en el poblado de la Edad del Bronce de El Trastejón (Zufre, Huelva)". En J. Campos, J. Aurelio y F. Gómez (eds.): Arqueología en el entorno del Bajo Guadiana. Actas del Encuentro Internacional de Arqueología del Suroeste. Diputación de Huelva. Huelva: 239-271.

INCHAURRANDIETA, R. (1869): "Notice sur la montagne funéraire de La Bastida, province de Murcie (Espagne)". Congrès International d'Anthropologie et d'Archéologie Préhistoriques (4 ${ }^{\mathrm{a}}$. Sesión, Copenhague, 1869). Kraus Reprint. Londres: 344-350.

Khalil, L. y BachmanN, H. (1981): "Evidence of copper smelting in Bronze Age Jericho". Journal of the Historical Metallurgy Society, 15 (2): 103-106.

LAMBERT, N. (1983): "Nouvelle contribution à l'étude du Chalcolitique de Mauritanie". En N. Échard (ed.): Métallurgies Africaines. Nouvelles contributiones. Mémoires de la Société des Africanistes, 9. París: 63-87.

lópez Mira, J. y Ortega Pérez, J. (1991): "Historia de Novelda. La Prehistoria 2". Excmo. Ayuntamiento de Novelda. Novelda.

T. P., 53, n. ${ }^{\circ} 1,1996$ 
LUENGO, J.M a . (1941): "El período eneolítico y la Edad del Bronce en la provincia de Léon". La Corona de Estudios I. Sociedad Española de Antropología, Etnografía y Floklore. Madrid: 125-140.

Lull, V. (1983): "La «Cultura» de El Argar (un modelo para el estudio de las formaciones económico-sociales prehistóricas)". Ed. Akal/Universitaria. Madrid.

MARÉCHAL, J. (1985): "Methods of ore roasting and the furnaces used". En P. Craddock y M. Hughes (eds.): Furnaces and Smelting Technology in Antiquity, British Museum Occasional Paper, 48. Londres: 29-41.

Martínez Peñarroya, J. y Sánchez Meseguer, J. (1988): "La Edad del Bronce en la Mancha suroriental. Aproximación socioeconómica". Actas del I Congreso de Historia de Castilla-La Mancha, II, Pueblos y culturas prehistóricas y protohistóricas (1). Comunidad de Castilla-La Mancha. Ciudad Real: 265-270.

MAYA, J. (1982): "Genó. Aitona". Les excavacions arqueológiques a Catalunya en els darrers anys, I. Departament de Cultura de la Generalitat de Catalunya. Barcelona: $159-160$

MAYA, J.; Rovira, S.; Cuesta, F. y Luigi, P. (1993): “Archeo-metallurgia del bronzo nel villaggio preromano de "La Campa Torres". SMI Review (Art and Technology), 17. Firenze: 85-94.

Molina, F.; Contreras, F.; Ramos, A.; Mérida, V.; ORTIZ, F. y RuIZ, V. (1986): "Programa de recuperación del registro arqueológico del Fortín 1 de Los Millares. Análisis preliminar de la organización del espacio". Del Paleolítico al Bronce Medio. Coloquio sobre el microespacio, 2 (Teruel, 1986). Arqueología Espacial, 8: 175-201.

MonTero, I. (1993): "Bronze Age metallurgy in southeast Spain". Antiquity, 67 (254): 46-67.

- (1994): "El origen de la metalurgia en el Sureste peninsular". Instituto de Estudios Almerienses. Almería.

Motos, F. DE (1918): “La Edad Neolítica en Vélez Blanco". Comisión de Investigaciones Paleontológicas y Prehistóricas, Memoria 19. Madrid.

Pérez Macías, J. y Frías, C. (1989): "La necrópolis de cistas de La Parrita (Nerva, Huelva) y los inicios de la metalurgia de la plata en las minas de Río Tinto". Cuadernos de Suroeste, 1: 11-21.

Ponsell, F. (1926): Excavaciones en la finca "Mas de Menente", término de Alcoy (Alicante). Memoria de los trabajos obtenidos en dichas excavaciones. Junta Superior de Excavaciones y Antigüedades, número general 78.

Priego, C. y Quero, S. (1992): "El Ventorro, un poblado prehistórico de los albores de la metalurgia". Estudios de Prehistoria y Arqueología Madrileñas, 8.

RotHENBERG, B. (1985): "Copper smelting furnaces in the Arabah, Israel: the archaeological evidence". En P. Craddock y M. Hughes (eds.): Furnaces and Smelting Technology in Antiquity. British Museum Occasional Paper, 48. Londres: 123-150.

- (1990): "Researches in the Arabah 1959-1984". Institute for Archaeo-Metallurgical Studies. Institute of Archaeology. University College London. Londres.

RothenBERG, B. y BlanCO, A. (1980): "Ancient copper mining and smelting at Chinflón (Huelva, SW Spain)". En P. Craddock (ed.): Scientific Studies in Early Mi- ning and Extractive Metallurgy. British Museum Occasional Paper, 20. Londres: 41-62.

RoviRA, S. (1989): "Recientes aportaciones para el conocimiento de la metalurgia primitiva en la provincia de Madrid: un yacimiento campaniforme en Perales del Río (Getafe, Madrid)". XIX Congreso Nacional de Arqueología, I (Castellón de la Plana, 1987). Zaragoza: 355-366.

ROVIRA, S. y MONTERO, I. (1994): "Metalurgia campaniforme y de la Edad del Bronce en la comunidad de Madrid". En C. Blasco (ed.): "El horizonte campaniforme de la región de Madrid en el centenario de Ciempozuelos". Universidad Autónoma de Madrid. Madrid: 137-171.

Rovira i HortalÀ, C. (1993): "Estudi arqueometal_lúrgic de l'Illa d'en Reixac-Ullastret (Baix Empordà)". Revista d'Arqueologia de Ponent, 3: 65-149.

Ruiz-GÁlvez, Ma.L. (1993): "El occidente de la Península Ibérica, punto de encuentro entre el Mediterráneo y el Atlántico a fines de la Edad del Bronce". Complutum, 4: 41-68.

SÁNCHEZ JIMÉNEZ, J. (1947): “Excavaciones y trabajos arqueológicos en la provincia de Albacete, de 1942 a 1946". Informes y Memorias, 15. Comisaría General de Excavaciones Arqueológicas. Madrid.

SAngmeister, E. y Schubart, H. (1981): Zambujal. Die Grabungen 1964 bis 1973. Madrider Beiträge, 5 (1). Verlag Philipp von Zabern. Mainz.

SARABIA, J. (1992): "Arqueología experimental. La fundición de bronce en la Prehistoria reciente". Revista de Arqueología, 130: 12-22.

Schubart, H. y SANGmeister, E. (1984): “Zambujal. Un asentamiento fortificado de la Edad del Cobre en Portugal". Revista de Arqueología, 37: 20-33.

SIRET, E. y L. (1890): "Las primeras edades del metal en el Sudeste de España”. Ed. Ed. Martorell. Barcelona.

SIRET, L. (1948): "El tell de Almizaraque y sus problemas". Cuadernos de Historia Primitiva, III: 117-124.

TYLECOTE, R. (1974): "Can copper be smelted in a crucible?". Journal of the Historical Metallurgy Society, 8 (1): 54.

- (1976): "A History of Metallurgy". The Metals Society. Londres.

- (1980): "Furnaces, crucibles, and slags". En T. Wertime y J. Muhly (eds.): "The Coming of the Age of Iron". Yale University. New Haven: 183-228.

- (1982): "Early copper slags and copper-base metal from the Agadez region of Niger". Journal of the Historical Metallurgy Society, 16 (2): 58-64.

Tylecote, R. y Merkel, J. (1985): "Experimental smelting techniques: achievements and future". En P. Craddock y M. Hughes (eds.): Furnaces and Smelting Technology in Antiquity. British Museum Occasional Paper, 48. Londres: 3-20.

WEISGERBER, G. (1978): "A new kind of copper slag from Tawi Aarja, Oman". Journal of the Historical Metallurgy Society, 12 (1): 40-43.

ZWICKER, U.; Greiner, H.; HofMANN, K. y ReITHINGER, M. (1985): "Smelting, refining and alloying of copper and copper alloys in crucible furnaces during Prehistoric up to Roman times". En P. Craddock y M. Hughes (eds.): Furnaces and Smelting Technology in Antiquity. British Museum Occasional Paper, 48. Londres: 103-115. 